\title{
The Effect of Realistic Mathematics Education on Academic Achievement, Motivation and Retention of Fifth Grade Students ${ }^{i}$
}

\author{
Selin Cengiz ${ }^{1}$, Eray Ĕgmir ${ }^{2, *}$ \\ ${ }^{1}$ The Ministry of National Education (MoNE), Konya, Turkey \\ ${ }^{2}$ Department of Educational Sciences, Faculty of Education, Afyon Kocatepe University, Afyonkarahisar, Turkey
}

Received December 15, 2021; Revised January 12, 2022; Accepted February 16, 2022

\section{Cite This Paper in the following Citation Styles}

(a): [1] Selin Cengiz, Eray Eğmir, "The Effect of Realistic Mathematics Education on Academic Achievement, Motivation and Retention of Fifth Grade Students," Universal Journal of Educational Research, Vol. 10, No. 3, pp. 225 - 239, 2022. DOI: 10.13189/ujer.2022.100305.

(b): Selin Cengiz, Eray Ĕgmir (2022). The Effect of Realistic Mathematics Education on Academic Achievement, Motivation and Retention of Fifth Grade Students. Universal Journal of Educational Research, 10(3), 225 - 239. DOI: 10.13189/ujer.2022.100305.

Copyright $\odot 2022$ by authors, all rights reserved. Authors agree that this article remains permanently open access under the terms of the Creative Commons Attribution License 4.0 International License

\begin{abstract}
In this study, the effect of Realistic Mathematics Education (RME) on fifth grade students' academic achievement, motivation and retention in "Data Processing" learning domain was investigated. In the research, quasi-experimental design with pre-test post-test control group was used. The research carried out in two secondary schools in the district of Bayat in Afyonkarahisar province in Turkey in the second term of 2018-2019 academic year was conducted with a total of 41 students, 19 of whom were in the experimental group and 22 of whom were in the control group. While the implementations were organized with the RME approach in the experimental group, the control group received instruction in line with the activities included in the Ministry of National Education secondary school mathematics curriculum. In this study, "Evaluation Form of Learning Outputs in Data Processing Learning Domain" and "Mathematical Motivation Scale" were used as data collection tools. The instruments were applied to the experimental and control groups as pre-test, post-test and retention test. As a result of the analysis, there were not any significant differences between achievement, motivation and retention scores of the experimental and control groups.
\end{abstract}

Keywords Realistic Mathematics Education (RME), Data Processing, Academic Achievement, Retention, Motivation

\section{Introduction}

Education is a significant concept that shapes the life of individuals and society. Education enables social advances and improves individuals' quality of life. It forms the basis of the developments of the advanced countries. The knowledge, skills, attitudes and behaviors required in the new century can only be transferred to individuals through education [1]. Being a universal language, mathematics is a significant area for individuals, society, scientific research and technological developments in the constantly developing world. That we come across mathematics in a number of areas makes it compulsory to learn this course.

In the mathematics curriculum in Turkey, it is aimed to train students as individuals who can produce knowledge, use that information they produce in their daily life, solve problems, think critically, be entrepreneurial, have communication skills, empathize, contribute to society and culture [2]. In the constructivist approach adopted in MoNE curricula, students take an active role in the learning-teaching process. By turning abstract mathematical expressions into concrete teaching materials, students' exploratory and independent thinking skills are developed [3]. In a constructivist lesson, first it is aimed to draw the attention of students, then a problem is presented and the prior knowledge of students is elicited. To come up with a solution to the problem, the students examine the problem in cooperation, produce hypotheses, develop 
solutions, share their ideas with their friends, listen to their friends' ideas, and review their own thoughts. Then each student decides what needs to be done to improve their knowledge structures. The teacher guides students and helps them in the thinking process [4]. Thanks to the contents that students can associate with their lives, the mathematics lesson attracts more attention and students grasp the importance of mathematics to a greater extent.

There are international examinations that give us the chance to assess the efficiency of education system in Turkey, and make comparisons with other countries. The results of the international exams such as TIMSS and PISA, which the International Association for the Evaluation of Educational Achievement (IEA) organizes every four years, are important indicators of the failure in mathematics. Turkey's performance in PISA 2018 increased compared to the PISA 2015. With 454 points in mathematics, Turkey rose from 50th place to 42nd place; however, this score is below the OECD average [1]. In the same vein, regarding the distribution of 8th grade mathematics achievements of the countries in TIMMS 2015, Turkey got 458 points and ranked 24th among 39 countries and scored below 500 points which is scale mean [2]. The data presented here prove that Turkish students' achievement in mathematics course is not satisfactory. More significance should be attached to mathematics teaching to enable improvement in Turkey's success in these types of performance measures.

Realistic Mathematics Education (RME) is employed through taking prominent practices in mathematics teaching into consideration. RME was first used by Freudenthal Institute in Holland as an approach in mathematics education. This theory which has been in use for about thirty years in Holland is also adopted in countries such as England, Spain, Germany, Denmark, the U.S.A., Brazil and Japan [5]. According to Freudenthal Institute, mathematics is a human activity, and it is not discovered but invented [6]. According to Gravemeijer (1994), in RME, instruction begins with real life problems and the need to do mathematics is taken as a basis [5]. Experiential cases should be presented to students to have them feel the need for mathematics and get them into a meaningful mathematical process. In RME, students should be sure of them and construct their own products [7].

In RME, the problem is not first presented with abstract principles, mathematical knowledge or rules. A problem is introduced and it is aimed to solve the problem, knowledge is organized and re-arranged and then concretized in order to understand the subject to a greater extent [8]. Freudenthal (1991) named the process which involves starting from real life problems and reaching the mathematical concept as "mathematization" [9]. Mathematization is reaching the mathematical concept, that is, formal knowledge, from the concept acquired through daily life. The first step of mathematization is horizontal mathematization. Horizontal mathematization is separating schemas, formulating, finding different ways of the given problem; that is, a transition from everyday life to the world of symbols. The second step of mathematization is vertical mathematization, which is defined as moving within the world of symbols and reaching concepts and formulas from symbols [5]. The RME approach is based on horizontal and vertical mathematization.

It is reported that RME approach increases students' achievement, and real life problems attract students' attention and change classroom atmosphere positively for learning [10]. It is also highlighted by educators that instruction with real life problems has a positive effect on increasing students' motivation and interest towards mathematics [11].

RME is a functional approach to achieving permanent learning through supporting students to make sense of concepts and make abstraction with the help of real life problems. In RME, students are motivated, and they feel that they are successful since learning occurs at their own pace. The motivated student then actively participates in activities. Students who solve problems successfully start to enjoy what they do. In RME, knowledge is acquired through discovery and making sense of real life through mathematization increases students' interests in lesson and thereby their motivation [12].

When the literature is examined, in the study conducted by [25] with secondary school 7th grade students, it was seen that the RME approach was more effective in increasing student achievement than the traditional approach in teaching multiplication with integers. In his study, [23] concluded that in the teaching of "Numbers and Operations, Algebra" unit outcomes, RME supported teaching applied to the experimental group increased the academic success of the students. [33] concluded that RME supported mathematics teaching is more effective than traditional methods in teaching the subject of 'Volume Measurement and Liquid Measurement Units' in 6th grades. [8], [34], [35], and [36] have also found that RME is effective in increasing student achievement.

It is seen that the teaching method based on the RME approach is mostly applied to the students at the secondary school level, but the studies conducted at the 5th grade level of secondary school are very few. In the literature, there is no study related to the "Data Processing" learning area. For this reason, the use of a teaching method based on the RME approach in the "Data Processing" learning field in the 5th grades of secondary school constitutes the originality of the research. It is thought that the research will contribute to the literature and will provide an exemplary application for mathematics teachers for RME.

\subsection{Purpose of the Study}

This research study aims to examine the effect of instructional activities designed in line with Realistic Mathematics Education on fifth grade students' academic achievement, motivation and retention in "Data 
Processing" learning domain. The study seeks to facilitate attaining the learning outcomes in "Data Processing" learning domain through associating them with students' daily life activities with the help of instruction based on RME. Since real life scenarios are at the forefront in the learning process, it is aimed to increase retention of the knowledge acquired in this process. An increase in students' motivation towards mathematics is expected, as well.

The problem statement of the current study is as follows: Is there a significant difference in terms of academic achievement, motivation and retention between the fifth grade students receiving instruction in line with RME approach and the fifth grade students receiving instruction in line with MoNE curriculum?

\section{Materials and Methods}

\subsection{Research Model}

This study employs quasi-experimental design with pretest-posttest control group out of quantitative research methods. In this design, available groups are arbitrarily assigned as control group and experimental group, and groups are compared through measurements before and after intervention. The difference between this design and experimental design is that the groups are not formed randomly in the beginning. Of the available groups, one is arbitrarily assigned as the experimental group and the other is assigned as the control group [13].

\subsection{Participants}

The participants of the study were formed through convenience sampling method. Convenience sampling method provides practicality and pace for research studies. In this method, the researcher selects a case which is close to the researcher and easy to access [14]. The schools in which this study was carried out were selected since the researcher was working in these schools, which provided easy access.

The population of the study consists of the fifth grade students studying Afyonkarahisar province of Turkey in 2018-2019 academic year. According to the organization of Turkish Educational System, fifth grade is the first year of secondary school term. Therefore, the students participating in the study are studying in the first year of secondary school and are 11 or 12 years old. The sample of the study consists of the fifth grade students studying in two lower secondary schools in Bayat district of Afyonkarahisar in the spring term of 2018-2019 academic year. In the sample, there are 41 students in total, 19 in the experimental group and 22 in the control group.

\subsubsection{Equalization of the Groups}

In the study, post-test achievement scores were made equal due to the fact that the significant difference between pre-test and post-test scores of the experimental and control groups would cause statistically incorrect results. Achievement scores attained by students in the experimental and control groups from pre-test and post-test were compared with independent samples t-test and the results are provided in Table 1 and Table 2.

Table 1. t-test results regarding pre-test scores of experimental and control groups

\begin{tabular}{|c|c|c|c|c|c|c|}
\hline Group & $\mathbf{N}$ & Mean & SD & df & $\mathbf{t}$ & $\mathbf{p}$ \\
\hline Control & 21 & 10.83 & 7.16 & \multirow{2}{*}{26.49} & \multirow{2}{*}{-3.375} & \multirow{2}{*}{$.00^{*}$} \\
\hline Experimental & 19 & 22.71 & 13.74 & & & \\
\hline
\end{tabular}

There is a significant difference in the means of achievement scores of the experimental and control groups in the pre-test, as evident in Table 1.

Table 2. t-test results regarding post-test scores of experimental and control groups

\begin{tabular}{ccccccc}
\hline Group & N & Mean & SD & df & t & p \\
\hline Control & 21 & 22.61 & 19.64 & & & \\
\cline { 1 - 5 } Experimental & 18 & 39.80 & 18.17 & & -2.819 & $.00 *$ \\
\hline
\end{tabular}

$* \mathrm{p}<.05$

As shown in Table 2, there is a significant difference in the means of achievement scores of the experimental and control groups in the post-test.

Dependent variable (post-test) achievement scores adjusted according to control variable (post-test) of the experimental and control groups by single-factor analysis of covariance are presented in Table 3 .

Table 3. Descriptive statistics of post-test achievement scores of the experimental and control groups

\begin{tabular}{cccc}
\hline Group & N & Mean & Adjusted Mean \\
\hline Control & 20 & 23.55 & 31.41 \\
\hline Experimental & 18 & 39.80 & 31.06 \\
\hline
\end{tabular}

$* \mathrm{p}<.05$

It is given in Table 3 that the difference between post-test achievement scores of students in experimental and control groups is 16.25. The difference between post-test achievement scores which are corrected according to pre-test achievement scores is 0.35 . In the final step, it can be argued that post-test achievement scores of experimental and control groups are equivalent to each other [17].

Dependent variable (retention test) achievement scores adjusted according to the control variable (post-test) of the experimental and control groups are presented in Table 4. 
Table 4. Descriptive statistics of retention scores of the experimental and control groups

\begin{tabular}{cccc}
\hline Group & N & Mean & Adjusted Mean \\
\hline Control & 20 & 18.81 & 24.93 \\
\hline Experimental & 18 & 36.50 & 30.03 \\
\hline p $<.05$ & & &
\end{tabular}

It is provided in Table 4 that the difference between retention test scores of students in experimental and control groups is 17.69. The difference between retention test scores which are corrected according to post-test achievement scores is 5.10. In the final step, it can be argued that retention test scores of experimental and control groups are equivalent to each other.

The students participating in the research should be made equal in terms of other variables in order to control the independent variables that are aimed to be tested in the study in the experimental groups. The purpose in controlling the variables is to increase the internal validity of the study and make sure that the result of the study stems from only the tested independent variable [17]. To this end, post-test achievement scores and retention test scores of the experimental and control groups were made equal. Since pre-test motivation scores of the experimental and control groups were equal to each other, no further analysis was needed to equalize them.

\subsection{Data Collection Tool}

In order to collect data, "Evaluation Form of Learning Outputs in Data Processing Learning Domain" (EFLODP) and "Mathematical Motivation Scale" (MMS) were used as pre-test and post-test. EFLODP was used again four weeks later to measure retention of knowledge.

Evaluation Form of Learning Outputs in Data Processing Learning Domain (EFLODP): The researchers first examined the fifth grade mathematics curriculum and determined learning outputs with regard to "data processing" learning domain in order to develop EFLODP to be used as pre-test, post-test and retention test in the study. In line with the learning outputs, table of specifications was prepared. A form of 27 questions was prepared out of learning output comprehension tests of TIMSS, PISA, The State Scholarship Exam and tests published by MoNE. The questions in these tests are open-ended and the students should interpret and solve the questions. The draft form of the instrument was presented to two mathematics teachers and three mathematics specialists to get their opinions about the form. Based on the feedback from them, the form was revised and the final form of EFLODP included 18 questions.

Mathematical Motivation Scale (MMS): "Mathematical Motivation Scale" was used in the current study to identify the effect of RME on students' mathematics motivation [15]. Permission to use the scale in the present study was obtained from the researchers who had developed the scale. MMS is in five-point Likert type and there are not any reverse-coded items in it. The items include the options of "I totally don't agree", "I don't agree", "I am not sure", "I agree", and "I totally agree". "I totally agree" scored 5 points and "I totally don't agree" scored 1 point. The internal consistency coefficient of the scale ranged from .85 to .94 and the item-total correlation values ranged from .62 to .89 .

\subsection{Collection of Data}

While the experimental group received mathematics instruction through lesson plans developed in line with RME, the control group received instruction with the existing mathematics curriculum. There were three learning outputs in the data processing learning domain of the fifth grade mathematics curriculum and 10 hours of lessons were allocated to units. The implementation took two weeks. The students in the experimental and control groups took the pre-tests one week before the implementation. The students then took the post-tests one week after the implementation. The study lasted for four weeks in total. Four weeks after the implementation, the students took the retention test.

\subsection{Data Analysis}

The quantitative data obtained through the instruments were analyzed through SPSS 22.00 (The Statistical Package for The Social Sciences) in line with the research problem and sub-problems. The scores of students in the experimental and control groups obtained in the achievement pre-test, achievement post-test and retention test showed normal distribution. Therefore, in the comparison of the two groups' means, paired sample t-test and independent samples t-test were used out of parametric tests.

Pre-test and post-test scores of the students in the experimental and control groups in motivation pre-test and post-test did not have a normal distribution. Therefore, parametric tests were not used in the comparison of the means of the two groups, and Mann-Whitney U test, out of non-parametric tests, was preferred [16].

A significant difference was identified between the scores of the experimental and control groups in achievement pre-test. To differentiate the effect of RME from the effects of other variables, one-way analysis of covariance (ANCOVA) was performed to compare post-test scores. Similarly, ANCOVA was used to compare retention scores of experimental and control groups [17].

The assumptions of ANCOVA are as follows:

- The sample subject to comparison of means is independent.

- The distribution of scores related to the dependent variable for each of the groups formed according to a group is normal. 
- In a randomized design, the relationship between dependent variable $(\mathrm{Y})$ and the covariate $(\mathrm{X})$ is linear.

- Within-group regression slopes (regression coefficients) are homogenous.

\subsection{Validity and Credibility}

Reliability is the degree of error-free measurement of results [18]. Since subjective effects could interfere with the scoring of open ended questions in EFLODP, it was evaluated by the researcher and another rater separately with the help of a holistic scoring key developed by Cansiz (2015). Each question in EFLODP could be scored with $0,1,2,3$ and 4 points. For inter-rater reliability, Cohen's Kappa inter-rater agreement analysis was carried out [16].

Cohen's Kappa $(\mathrm{K})$ coefficients for the scores given to 18 questions in EFLODP pre-test, post-test and retention test by two raters are provided in Table 5 .

Table 5. Results of Cohen's Kappa Analysis regarding Students' Scores in Experimental and Control Groups

\begin{tabular}{cccc}
\hline Tests & $\begin{array}{c}\text { Number of } \\
\text { Measurement }\end{array}$ & Kappa Value & p \\
\hline Pre-test & 40 & .685 & .000 \\
\hline Post-test & 39 & .551 & .000 \\
\hline Retention test & 39 & .657 & .000 \\
\hline
\end{tabular}

Landis and Koch (1977) suggest the interpretation of the Kappa value as follows: " $\leqslant 0.20$ weak; $0.21-0.40$ medium; 0.41-0.60 good; 0.61-0.80 very good; 0.81-1.00 perfect" [16]. According to data obtained from the holistic evaluation key used in the assessment of EFLODP, the related coefficient is .685 for the pre-test, .551 for the post-test and .657 for the retention test. These values reveal that there are good and very good agreements among the two raters' scores in pre-test, post-test and retention test.

\subsection{Learning and Teaching Processes in Experimental and Control Groups}

The activities prepared for the research were applied to the experimental group for two weeks, five hours per week. The students were divided into heterogeneous groups within the framework of the cooperation principle of RME. The fact that the researcher is also the mathematics teacher of the students and knows the students well provided an advantage in the formation of heterogeneous groups. Care was taken to ensure that all students actively take part in group work. The distribution of the applications made in the experimental group during the research process is as follows:
- The students were informed about RME and the application process. Pre-tests (EFLODP and MMS) were applied.

The class was divided into groups and the rows were arranged in cluster order. Cinema, School Trip, Waste of Bread, School Representative, and Environmental Awareness activities were implemented. Activity sheets were distributed to the groups in order. With these activities, it is aimed that students discover how a research question should be. After the activities, evaluation questions created by the researcher were asked.

- Election, Birthday, Book Fair, How Many Letters in Your Name? activities have been implemented. Activity sheets were distributed to the groups in order. With these activities, it is aimed that the students discover ways to interpret the data obtained with the research questions more easily. It is aimed to explore the column chart and frequency table using the scoreboard they have learned before. After the activities, evaluation questions created by the researcher were asked.

- Weather, Broadcast Flow, Let's Compare the Heights 1, Compare the Heights 2, Sheep Production activities were applied. Activity sheets were distributed to the groups in order. With the given activities, it is aimed that the students understand the problems given with the column chart or frequency table and determine the situations that cause misinterpretations. After the activities, evaluation questions created by the researcher were asked.

- Number of Students, Passing Grade and Cycling Trip activities were applied. Activity sheets were distributed to the groups in order. In the applied activities, it is aimed that the students understand the problems given with the column chart or frequency table and reach the solution of the problem. After the activities, evaluation questions created by the researcher were asked.

- Post-tests and retention tests (EFLODP and MMS) were applied.

In the control group, while the lessons continued in their normal course, the textbook was used for evaluation and the exercises were provided by the students. Applications made in the control group during the research process are as follows:

- Students were informed about what to do during the lesson. Pre-tests (EFLODP and MMS) were applied.

- The lessons were taught with the activities in the mathematics textbook, which was prepared according to the current curriculum. Let's apply what we learned section used for evaluation.

- Post-tests and retention tests (EFLODP and MMS) were applied. 


\section{Findings}

\subsection{Findings Regarding Achievement}

The achievement scores obtained by the students in the experimental and control groups from the pre-test and post-test were compared through paired samples t-test and the results are presented in Table 6 and Table 7.

Table 6. t-test results regarding pre-test and post-test scores of the experimental group

\begin{tabular}{ccccccc}
\hline Test & N & Mean & SD & df & t & p \\
\cline { 1 - 4 } Pre-test & 18 & 23.75 & 13.35 & & & \\
\cline { 1 - 3 } Post-test & 18 & 39.80 & 18.17 & & -5.305 & $.00^{*}$ \\
\hline p $<.05$ & & & & & & \\
\hline
\end{tabular}

As is given in Table 6, a statistically significant difference was found between the pre-test mean score $\left(^{-} \mathrm{X}\right.$ $=23.75)$ and post-test mean score $\left({ }^{-} X=39.80\right)$ of the students in the experimental group $\left[\mathrm{t}_{(17)}=-5.305, \mathrm{p}<.05\right]$. The paired samples t-test reveals whether there is a significant difference between the means of two groups; however, it does not inform us about the size of this difference, that's why effect size is separately calculated in this study [16]. In t-test, the effect size (d) can be calculated with the formula below (after applying the formula, the absolute value of the result is taken):

$$
\begin{gathered}
\mathrm{N}=\text { Number of students in the experimental group } \\
\qquad \begin{array}{c}
\mathrm{d}=\mathrm{t} / \sqrt{ } \mathrm{N}[17] \\
\mathrm{d}=(-5.305) / \sqrt{ } 18=1.25
\end{array}
\end{gathered}
$$

The sign before the effect size is not significant and it may get any value. In general, $d$ value is considered as small for 0.2 , medium for 0.5 , big for 0.8 and very big for above $1[17]$. $\mathrm{d}$ value obtained in this study is 1.25 , which means that the difference between pre-test and post-test scores of the students in the experimental group is very high.

Table 7. t-test results regarding pre-test and post-test scores of the control group

\begin{tabular}{ccccccc}
\hline Test & N & Mean & SD & df & t & p \\
\cline { 1 - 4 } Pre-test & 20 & 10.32 & 6.94 & & & \\
\cline { 1 - 3 } Post-test & 20 & 23.55 & 19.67 & & -3.909 & $.00^{*}$ \\
\hline $\mathrm{p}<.05$ & & & & & & \\
\hline
\end{tabular}

As is given in Table 7, a statistically significant difference was found between the pre-test mean score $\left(^{-} \mathrm{X}\right.$ $=6.94)$ and post-test mean score $\left({ }^{-} X=19.67\right)$ of the students in the control group $\left[\mathrm{t}_{(19)}=-3.909, \mathrm{p}<.05\right]$. The effect size was calculated as there was a significant difference.

$$
\mathrm{d}=(-3,909) / \sqrt{ } 20=0.87
$$

The value obtained in this analysis $(d=0.87)$ shows that the difference between pre-test and post-test scores of the students in the control group is very high.

ANCOVA was performed to compare achievement post-test scores of the students in the experimental and control groups when the effect of achievement pre-test scores was controlled. Whether the assumptions of ANCOVA were met or not was checked before moving on to the analysis. First, the groups of comparison should be independent. As each student was in only one group in this study, this assumption was met. Second, scores regarding the dependent variable should have a normal distribution in each of the groups of comparison. Results of normality test regarding achievement post-test scores,

\begin{tabular}{|c|c|c|c|c|c|c|c|}
\hline & Group & KS & SW & Skew. & Std. Error & Kurt. & Std. Error \\
\hline \multirow{2}{*}{$\begin{array}{l}\text { Post- test } \\
\text { score }\end{array}$} & Control & .052 & .040 & 1.25 & .50 & .92 & .97 \\
\hline & Exp. & .200 & .135 & -.37 & .53 & -1.19 & 1.03 \\
\hline
\end{tabular}
determined as the dependent variable, are provided in Table 8 .

Table 8. Normality test results of achievement post-test scores of the experimental and control groups

KS: Kolmogrov-Smirnov; SW: Shapiro Wilk 
Assuming that data with skewness and kurtosis coefficients in the range of -2.0 to +2.0 have normal distribution [32], both the normality tests and Skewness and Kurtosis values of the students' post-test means suggest a normal distribution.

Third, there should be a linear relationship between post-test scores, which is the dependent variable, and pre-test scores, which is the control variable. The linearity of the relationship can be visually checked with the scatter plot. This process should be performed separately for each group [17]. The scatter plots are provided in Figure 1 and Figure 2.

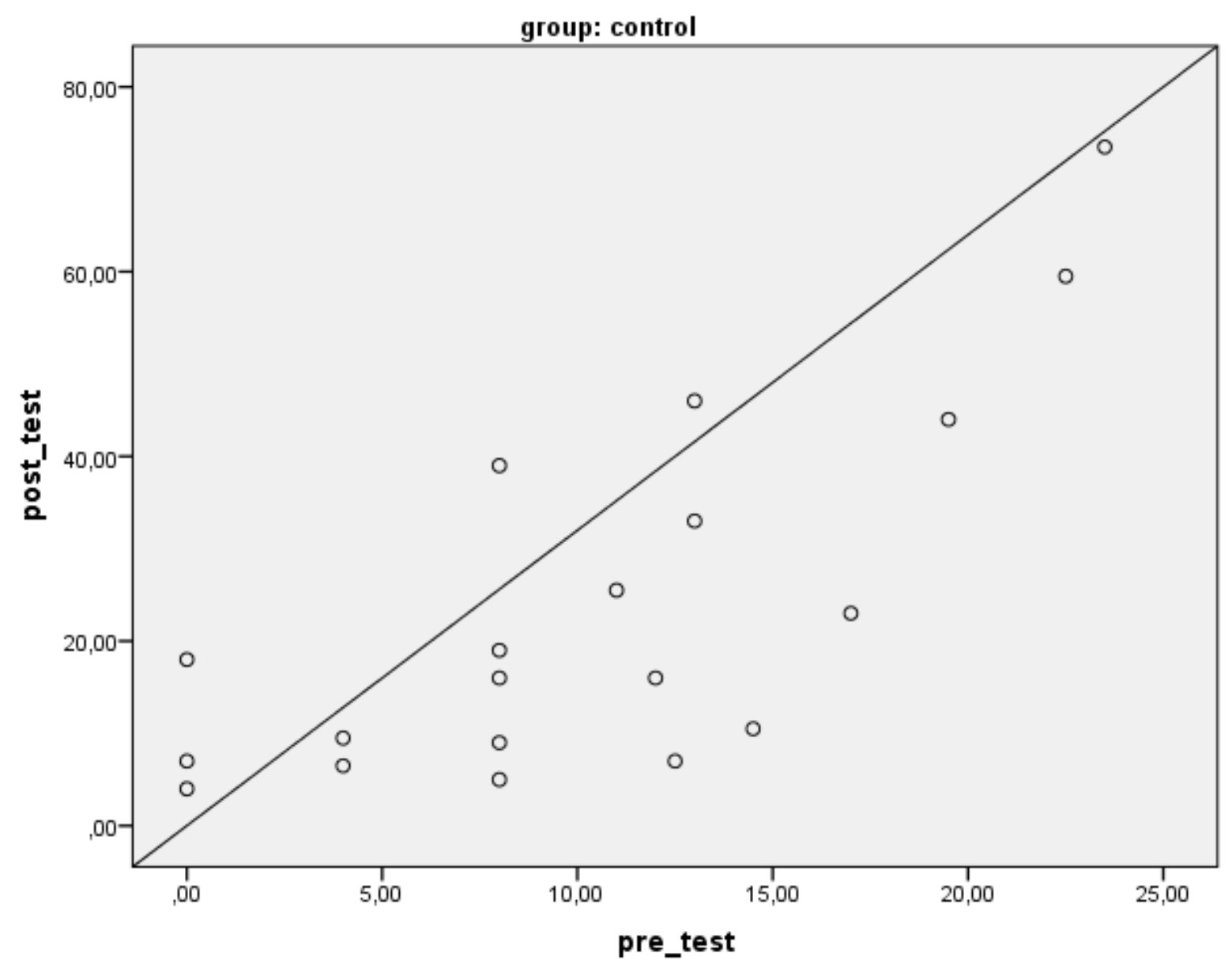

Figure 1. The scatter plot showing the relationship between pre-test and post-test achievement scores of the control group 
group: experimental

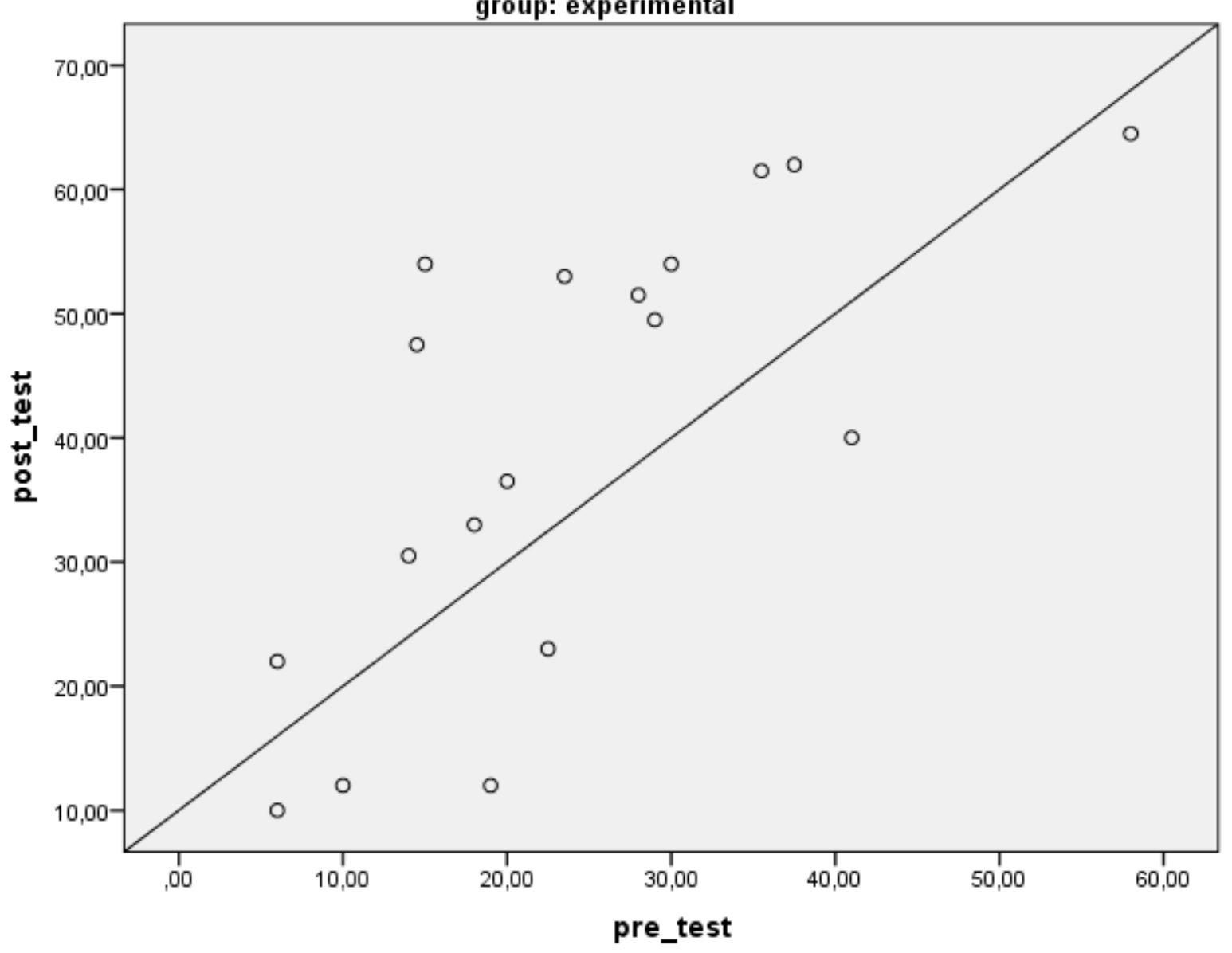

Figure 2. The scatter plot showing the relationship between pre-test and post-test achievement scores of the experimental group

Table 9. Simple Linear Regression Analysis Results regarding the Relationship between Pre-test and Post-test Achievement Scores of the Experimental and Control Groups

\begin{tabular}{cccccc}
\hline Group & Model & R & R Square & Adjusted R Square & Standard Error \\
\hline Control & 1 & $.755 \mathrm{a}$ & .569 & .545 & 13.262 \\
\hline Experimental & 1 & $.708 \mathrm{a}$ & .502 & .471 & 13.226 \\
\hline
\end{tabular}

Table 10. Results of the Pre-test Achievement Scores and between-group Effect Analysis

\begin{tabular}{cccccc}
\hline & \multicolumn{2}{c}{ Dependent Variable: Post-test } & & \\
\hline Source & Sum of Squares & df & Mean of Squares & F & p \\
\hline Adjusted Model & $9507.454 \mathrm{a}$ & 3 & 3169.151 & 18063 & .000 \\
\hline Intercept & 829.198 & 1 & 829.198 & 4.726 & .037 \\
\hline Group & 581.674 & 1 & 581.674 & 3.315 & .308 \\
\hline Pre-test & 6768.939 & 1 & 6768.939 & 38.580 & .000 \\
\hline Group * Pre-test & 966.504 & 1 & 966.504 & 5.509 & .202 \\
\hline Error & 5965.421 & 34 & 175.454 & & \\
\hline Total & 52582.250 & 38 & & & \\
\hline Adjusted Total & 15472.875 & 37 & & & \\
\hline & a. R Squared $=.614$ (Adjusted R Squared $=.580)$ & & \\
\hline
\end{tabular}

In the next step, the degree and significance of this relationship can be examined through simple linear regression test by considering pre-test achievement score as predictive variable and post-test achievement score as 
predicted variable.

The scatter plot and regression analysis results suggest that the third assumption is met.

Forth, the regression coefficients in the groups (regression slopes) need to be homogenous (equal). To meet this assumption, analysis regarding "arbitrary adjusted model" involving the mutual interaction between pre-test achievement score, which is the control variable, and Realistic Mathematics Education, which is the independent variable, was performed. The results of this analysis are presented in Table 10.

Table 10 reveals that the value of significance in the row where there are two variables (Group*Pre-test) is $.202>.05$, and therefore, there is not a significant difference between regression slopes. This finding suggests that the forth assumption is met.

After meeting the assumptions, ANCOVA was performed. The results are presented in Table 11 .

According to these results, there is not a significant difference between the post-test achievement score means adjusted according to the groups' pre-test achievement scores $[F(1-35)=30.484, p>.05]$. In other words, the implemented RME has not been effective on students' achievement.

\subsection{Findings regarding Motivation}

The motivation scores obtained by the students in the experimental group from the pre-test and post-test were compared with paired samples t-test and the results are presented in Table 12.

Pre-test motivation score mean $\left({ }^{-} X=116.94\right)$ of the students in the experimental group is higher than their post-test score mean $\left({ }^{-} X=116.15\right)$. There was very little change in the motivation score of the experimental group before and after the implementation. It can be said that the mean was stable and there was not a significant difference $\left[\mathrm{t}_{(18)}=.384, \mathrm{p}>.05\right]$.

The motivation scores obtained by the students in the control group from the pre-test and post-test were compared with paired samples t-test and the results are presented in Table 13.

Pre-test motivation score mean $(-X=117.86)$ of the students in the control group is higher than their post-test score mean $\left({ }^{-} X=111.90\right)$. Motivation scores of the control group decreased after the implementation, which means their motivation changed negatively; however, this difference is not significant $\left[\mathrm{t}_{(21)}=1.710, \mathrm{p}>.05\right]$.

Post-test motivation scores of students in the experimental and control groups were compared with Mann-Whitney $U$ test and the results are presented in Table 14.

Gain scores of the students in the experimental and control groups are examined in Table 14. Gain scores were calculated by taking the difference between motivation post-test and pre-test scores. There was not a significant difference between the gain scores of students in the experimental and control groups $(U=167.50, p>0.05)$ [16].

Table 11. Results of ANCOVA of Adjusted Post-test Achievement Means

\begin{tabular}{cccccc}
\hline Source & Sum of Squares & df & Mean of Squares & F & p \\
\hline Pre-test (Regression) & 6037.595 & 1 & 6037.595 & 30.484 & .00 \\
\hline Group & .800 & 1 & .800 & .004 & .95 \\
\hline Error & 6931.925 & 35 & 198.055 & \\
\hline Total (Adjusted) & 15472.875 & 37 & & \\
\hline
\end{tabular}

Table 12. t-test Results regarding Pre-test and Post-test Motivation Scores of the Experimental Group

\begin{tabular}{ccccccc}
\hline Test & N & Mean & SD & df & t & p \\
\hline Pre-test & 19 & 116.94 & 13.24 & \multirow{2}{*}{18} & \multirow{2}{*}{.384} & .70 \\
\hline Post-test & 19 & 116.15 & 13.11 & & & \\
\hline
\end{tabular}

Table 13. t-test Results regarding Pre-test and Post-test Motivation Scores of the Control Group

\begin{tabular}{ccccccc}
\hline Test & N & Mean & SD & df & t & p \\
\hline Pre-test & 22 & 117.86 & 13.78 & 21 & \multirow{2}{*}{1.710} & .10 \\
\hline Post-test & 22 & 111.90 & 13.48 & & & \\
\hline
\end{tabular}

Table 14. Mann-Whitney U Test Results regarding Gain Scores of the Experimental and Control Group

\begin{tabular}{cccccc}
\hline Group & N & Mean Rank & Sum of Ranks & U & p \\
\hline Control & 22 & 19.11 & \multirow{2}{*}{167.50} & .277 \\
\hline Experimental & 19 & 23.18 & 440.50 & & \\
\hline
\end{tabular}




\subsection{Findings regarding Retention}

The post-test scores and retention scores of the students in the experimental group were compared with paired samples t-test and the results are provided in Table 15.

Table 15. t-test Results regarding Post-test and Retention test Scores of the Experimental Group

\begin{tabular}{ccccccc}
\hline Test & $\mathbf{N}$ & Mean & SD & df & t & p \\
\hline Post-test & 18 & 39.80 & 18.17 & & & \\
\cline { 1 - 3 } $\begin{array}{c}\text { Retention } \\
\text { Test }\end{array}$ & 18 & 36.50 & 20.74 & 1.348 & .19 \\
\hline
\end{tabular}

Post-test score mean $\left({ }^{-} X=39.80\right)$ of the students in the experimental group is higher than their retention test score mean $(-X=36.50)$. The scores of the retention test which was taken by the students four weeks after the implementation was reduced when compared to post-test scores. This suggests that the knowledge was not retained by the students at the expected level. However, this decrease is not significant $\left[\mathrm{t}_{(17)}=1.348, \mathrm{p}>.05\right]$.

The post-test scores and retention scores of the students in the control group were compared with paired samples t-test and the results are provided in Table 16.

Table 16. t-test Results regarding Post-test and Retention test Scores of the Control Group

\begin{tabular}{ccccccc}
\hline Test & N & Mean & SD & df & t & $\mathbf{p}$ \\
\hline Post-test & 19 & 23.78 & 20.27 & & & \\
\cline { 1 - 3 } Retention & 19 & 18.81 & 15.25 & & 1.951 & .06 \\
\hline
\end{tabular}

Post-test score mean $\left({ }^{-} \mathrm{X}=23.78\right)$ of the students in the control group is higher than their retention test score mean $\left({ }^{-} \mathrm{X}=18.81\right)$. The scores of the retention test which was taken by the students four weeks after the implementation reduced when compared to post-test scores. This suggests that the knowledge was not retained by the students at the expected level. However, this decrease is not significant $\left[\mathrm{t}_{(17)}=1.951, \mathrm{p}>.05\right]$.

ANCOVA was performed to compare retention post-test scores of students in the experimental and control groups when the effects of achievement post-test scores were controlled. Whether the assumptions of ANCOVA were met or not was checked before moving on to the analysis. First, the groups of comparison should be independent. As each student was in only one group in this study, this assumption was met. Second, scores regarding the dependent variable should have a normal distribution in each of the groups of comparison. Results of normality test regarding retention test scores, determined as the dependent variable, are provided in Table 17.

Assuming that data with skewness and kurtosis coefficients in the range of -2.0 to +2.0 have a normal distribution [32], both the normality tests and Skewness and Kurtosis values of the students' retention test means suggest a normal distribution.

Third, there should be a linear relationship between retention test scores, which is the dependent variable, and post-test achievement scores, which is the control variable. The linearity of the relationship can be visually checked with the scatter plot. This process should be performed separately for each group [17]. The scatter plots are provided in Figure 3 and Figure 4.

Table 17. Normality test results of retention scores of the experimental and control groups

\begin{tabular}{ccccccccc}
\hline & Group & KS & SW & Skew. & Std. Error & Kurt. & Std. Error \\
\hline \multirow{2}{*}{ Ret. Score } & Control & .200 & .081 & 1.04 & .51 & .75 & .99 \\
\cline { 2 - 9 } & Exp. & .200 & .240 & .027 & .52 & -1.38 & 1.01 \\
\hline
\end{tabular}

KS: Kolmogrov-Smirnov; SW: Shapiro Wilk 


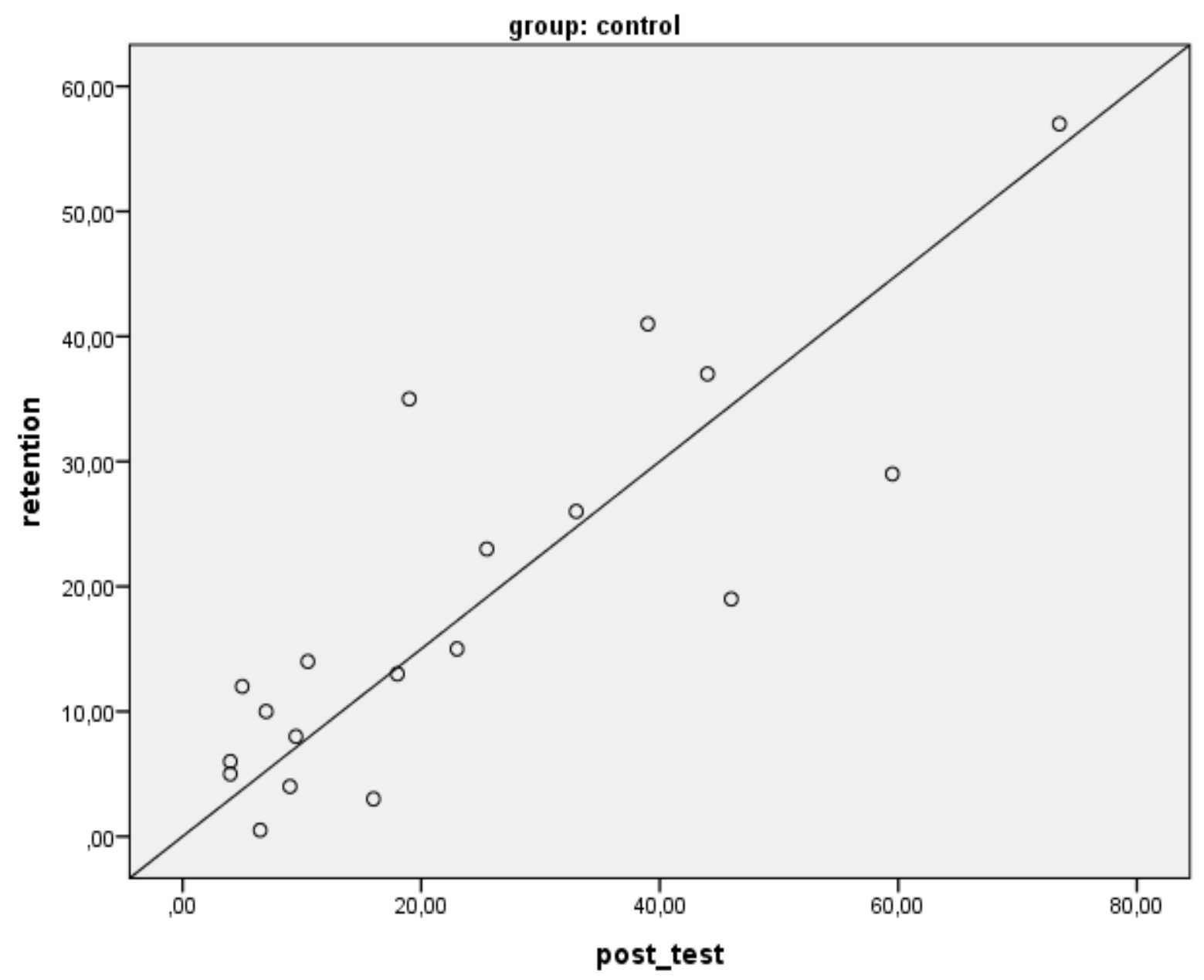

Figure 3. The scatter plot showing the relationship between retention test and post-test achievement scores of the experimental group 


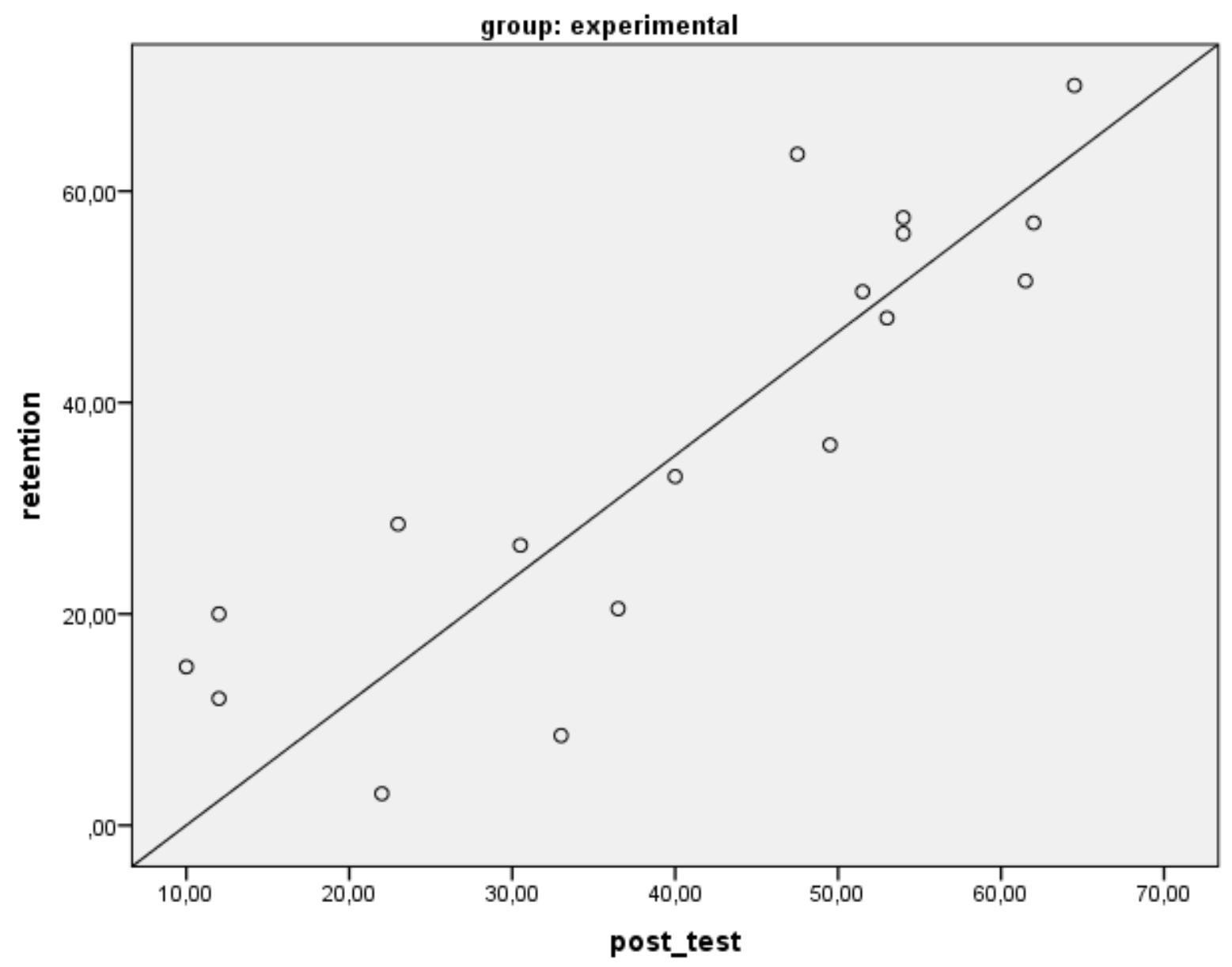

Figure 4. The scatter plot showing the relationship between pre-test and post-test achievement scores of the control group

Table 18. Simple Linear Regression Analysis Results regarding the Relationship between Retention Test and Post-test Achievement Scores of the Experimental and Control Groups

\begin{tabular}{cccccc}
\hline Group & Model & R & R Square & $\begin{array}{c}\text { Adjusted } \\
\text { R Square }\end{array}$ & Standard Error \\
\hline Control & 1 & $.841^{\mathrm{a}}$ & .708 & .690 & 8.486 \\
\hline Exp. & 1 & $.865^{\mathrm{a}}$ & .749 & .733 & 10.722 \\
\hline
\end{tabular}

Table 19. Results of the Post-test Achievement Scores and between-group Effect Analysis

\begin{tabular}{cccccc}
\hline & \multicolumn{2}{c}{ Dependent Variable: Retention } & & \\
\hline Source & Sum of Squares & df & Mean of Squares & F & p \\
\hline Adjusted Model & $11334.642^{\mathrm{a}}$ & 3 & 3778.214 & 40.691 & .000 \\
\hline Intercept & 1.927 & 1 & 1.927 & .021 & .886 \\
\hline Group & 92.596 & 1 & 92.596 & .997 & .325 \\
\hline Pre-test & 8386.59 & 1 & 8386.59 & 90.322 & .000 \\
\hline Group * Pre-test & 402.015 & 1 & 402.015 & 4.330 & \\
\hline Error & 3064.115 & 33 & 92.852 & & \\
\hline Total & 42215.250 & 37 & & & \\
\hline Adjusted Total & 14398.757 & 36 & & & \\
\hline & a. R Squared $=.787$ (Adjusted R Squared $=.768)$ & &
\end{tabular}


In the next step, the degree and significance of this relationship can be examined through simple linear regression test by considering post-test achievement score as predictive variable and retention test score as predicted variable.

The scatter plot and regression analysis results suggest that the third assumption is met.

Forth, the regression coefficients in the groups (regression slopes) need to be homogenous (equal). To meet this assumption, analysis regarding "arbitrary adjusted model" involving the mutual interaction between post-test achievement score, which is the control variable, and Realistic Mathematics Education, which is the independent variable, was performed. The results of this analysis are presented in Table 19.

Table 19 reveals that the value of significance in the row where there are two variables (Group*Post-test) is $.054>.05$, and therefore, there is not a significant difference between regression slopes. This finding suggests that the forth assumption is met.

After meeting the assumptions, ANCOVA was performed. The results are presented in Table 20.

Table 20. Results of ANCOVA of Adjusted Retention Test Achievement Means

\begin{tabular}{cccccc}
\hline Source & $\begin{array}{c}\text { Sum of } \\
\text { Squares }\end{array}$ & df & $\begin{array}{c}\text { Mean of } \\
\text { Squares }\end{array}$ & F & p \\
\hline $\begin{array}{c}\text { Pre-test } \\
\text { (Regression) }\end{array}$ & 8041.975 & 1 & 8041.975 & 78.885 & .00 \\
\hline Group & 203.123 & 1 & 203.123 & 1.992 & .16 \\
\hline Error & 3466.13 & 34 & 101.945 & & \\
\hline Total (Adjusted) & 14398.757 & 36 & & & \\
\hline
\end{tabular}

According to these results, there is not a significant difference between the retention test score means adjusted according to the groups' post-test achievement scores $[F(1-34)=78.885, p>.05]$. In other words, the implemented RME has not been effective on students' achievement.

\section{Conclusions}

According to the results of the analyses, a significant difference was identified between achievement post-test and pre-test score means of the students in the experimental and control groups. Although the effect size was high in the experimental group, it was not high in the control group. A significant difference was not found between post-test scores adjusted by pre-test scores of the students in the experimental and control groups. [19], [20] and [21] report similar results. Yet, [22] and [23] report contrary results.

There was not a significant difference between motivation pre-test and post-test score means of the students in the experimental group. There was a decrease in the motivation pre-test and post-test means of the students in the control group; however, there was not a statistically significant difference. There was not a significant difference between the gain scores of the two groups, as well. These results are in parallel with the results reported by [24] and [25]. On the other hand, [26], [27] and [28] found adverse results.

It was revealed that the achievement post-test score means of the students in the experimental and control groups were higher than their retention test score means; however, this difference was not statistically significant. The gain scores were calculated with the difference between retention test scores and post-test scores. There was not a statistically significant difference between gain scores of the both groups. Studies by [29] and [30] lend their support to this finding. However, retention was positively affected in the studies by [26] and [23].

Based on the results of the current study, it cannot be solidly argued that instruction supported with RME is more effective than instruction based on existing curriculum in increasing students' academic achievement in "Data Processing" learning domain. It is thought that factors such as that duration of implementation was short, that effect was not apparent in this particular learning domain, and that the participating students were in the first cycle of lower secondary school should be taken into consideration in interpreting the results. Fifth grade students may not have performed as expected since they were in the process of adapting to different teachers for different lessons. Also, hence, the MoNE switched to constructivism after 2005, the teaching and activities in the current program are in line with the constructivist logic. The reason why there was no significant difference between the scores of the students in the experimental and control groups is the effects of this situation.

This study put forth that instruction supported with RME did not affect students' motivation in either positive or negative way. This may be accounted for with the fact that there are not apparent changes in the motivations of young learners in short periods of time [31].

Despite the fact that the fifth grade students do not have a culture of discussion, the students participating in the current study had an exchange of ideas through cooperating with their peers. The students who did not have interest in the lesson, got bored during the instruction and did not want to participate in the activities in the instruction process based on the existing curriculum participated actively in lessons in which RME was employed. Each student could solve the problems in line with their paces since they had in-group and within-group cooperation. It may be suggested that if students receive instruction supported with RME for longer periods of time, their love for mathematics and thereby their achievement in mathematics might increase.

In education, the aim is not to provide students with the ready-made knowledge but to have them realize that they can learn with their own efforts. When students learn pieces of knowledge off their own bat, their knowledge will be current and real, which RME provides to students. 


\section{Suggestions}

- Qualitative studies should be carried out to thoroughly examine the effects of RME.

- The studies in the literature dwelling on RME approach are often related to a single learning domain. RME can be employed with multiple learning domains.

- Studies can be conducted to examine how much $\mathrm{RME}$ is represented in the current official Maths curriculum.

- Factors related to students, teachers, and learning environment that affect the implementation of RME can be investigated.

- Conceptual studies can be carried out to develop RME with computer-assisted teaching.

\section{REFERENCES}

[1] Ministry of National Education (MoNE). "PISA 2018 Turkey Preliminary Report", 2019. Retrieved from http://www.meb.gov.tr/meb_iys_dosyalar/2019_12/03105 347_PISA_2018_Turkiye_On_Raporu.pdf.

[2] Ministry of National Education (MoNE). Secondary school mathematics curriculum, Head Council of Education and Morality, Ankara, 2015.

[3] T. Tutak, Ü. İç, Z. Gün, N. Emül. "Evoluvation of primary school teachers' ideas about new mathematics curriculum at the period between 2006 and 2009: Elazığ sample". e-Journal of New World Sciences Academy, Vol. 4, No. 3, pp. 1034-1045, 2008.

[4] B. Oral. "Learning and teaching theories and approaches". Pegem Akademi Publishing, Ankara, 2018.

[5] Özkaya., G. Aksu. "Realistic mathematics education". Maya Academy, Ankara, 2017.

[6] M. Van den Heuvel-Panhuizen. "Mathematics education in the Netherlands: A guided tour". Freudenthal Institute Cd-rom for ICME9. Utrecht University, 2000.

[7] K. Gravemeijer. "Learning trajectories and local instruction theories as means of support for teachers in reform mathematics education". Mathematical Thinking and Learning, Vol. 6, No. 2, pp. 105-128, 2004.

[8] E. Çilingir, P. D. Artut. "The effect of realistic mathematics education approach on primary school students' success, visual mathematics literacy self-efficacy perceptions and problem solving attitudes". Turkish Journal of Computer and Mathematics Education, Vol. 7, No. 3, pp. 578-600, 2016.

[9] C. Alacac1, "Realistic mathematics education," in Theories of mathematics education Pegem Akademi Publishing, Ankara, 2016.

[10] E. Özdemir, D. Üzel. "The effect of realistic mathematics education on student achievement and student opinions towards instruction". Journal of Hacettepe University Faculty of Education, Vol. 40, No. 40, pp. 332-343, 2011.

[11] G. Karakoç, C. Alacacı. "Real world connections in high school mathematics curriculum and teaching". Turkish Journal of Computer and Mathematics Education, Vol. 6, No 1, pp. 31- 46, 2015.

[12] R. Çetin. "The effect of realistic mathematics teaching on the motivation of secondary school sixth grade students" (Unpublished Master Thesis). Kahramanmaraş Sütçü İmam University, 2018.

[13] N. Karasar. "Scientific research method concepts principles techniques". Nobel Publishing, Ankara, 2018.

[14] Yıldırım, H. Şimşek. "Qualitative research methods in the social sciences”. Seçkin Publishing, Ankara, 2005.

[15] S. Aktan, E. Tezci. "The mathematical motivation scale (mms) study of reliability and validity". The Journal of Academic Social Science Studies, Vol. 6, pp. 57-77, 2013.

[16] Can. "Quantitative data analysis in the research process with SPSS" Pegem Akademi Publishing, Ankara, 2017.

[17] Ş. Büyüköztürk. "Manual of data analysis for social sciences" Pegem Akademi Publishing, Ankara, 2015.

[18] S. Tekindal. "Creating a tool for measuring affective traits" Pegem Akademi Publishing, Ankara, 2015.

[19] Ş. Cansız. "The effect of the realistic mathematic education approach on students' mathematical achievement and creative thinking skills" (Unpublished Doctoral Dissertation). Atatürk University, 2015.

[20] M. Can. "A study regarding the effect of realistic mathematics education approach on the success of the students in third grades of primary education on measurement and permanency of acquired knowledge" (Unpublished Master Thesis). Abant İzzet Baysal University, 2012.

[21] R. Akkaya. "The investigation of knowledge construction process of concepts in probability and statistical learning field according to the realistic mathematic education and constructivism theory" (Unpublished Doctoral Dissertation). Uludağ University, 2010.

[22] M. Özkan. "The impact of realistic mathematics education approach on student success while teaching algebra at 6th grade" (Unpublished Doctoral Dissertation). Gazi University, 2019.

[23] H. Erdoğan, "The effect of realistic mathematics education activities on students' achievement, retention levels and reflective thinking skills" (Unpublished Master Thesis). Pamukkale University, 2018.

[24] L. Özkürkçüler. "Effects of realistic mathematics educations based instruction on 4th grade students" (Unpublished Doctoral Dissertation). Aydin Adnan Menderes University, 2019.

[25] Z. A. Ünal. "The effects realistic mathematics education on 7th grade students' achievements and attitudes toward mathematics". (Unpublished Master Thesis). Atatürk University, 2008.

[26] Kan. "The effect of realistic mathematics education method 
on student's success for primary school 4th grade fractions sub-learning area" (Unpublished Master Thesis). Ege University, 2009.

[27] Yonucuoğlu. "The effects of realistic mathematics education on 7th grade students' achievements and motivations in area of quadrilaterals" (Unpublished Master Thesis). Gaziantep University, 2018

[28] Z. Çakır. "The impact of students? Success and attitude towards math, carrying out an education supported by RME including 'algebra and field measurement? Subject of primary school 6th grades" (Unpublished Master Thesis). Zonguldak Karaelmas University, 2011.

[29] Y. Akkaya. "Analyzing the effect of realistic mathematics education approach on success, attitude and retention on secondary 9th class mathematics teaching" (Unpublished Master Thesis). Adnan Menderes University, 2019.

[30] N. G. Aydın. "Effect of realistic mathematics education in teaching fractions to the third grade primary school students on achievement, retention and attitude" (Unpublished Master Thesis). Abant İzzet Baysal University, 2014.

[31] N. Yenice, G. Saydam, S. Telli. "Determining Factors Effecting on Primary School Students' Motivation towards
Science Learning". Journal of Ahi Evran University Kirsehir Education Faculty, Vol. 13, No. 2, pp. 231-247, 2012.

[32] D. George \& P. Mallery. "SPSS for Windows Step by Step: A Simple Guide and Reference 11.0 Update". Pearson Education, Inc, United States of America, 2003.

[33] T. E. Taş. "The effect of realistic mathematics education supported teaching method on the mathematics achievement and attitudes of 6th grade primary school students" (Unpublished Master Thesis). Çukurova University, 2018.

[34] Hirza, Y. S. Kusumah, D. Darhim \& Z. Zulkardi. "Improving intuition skills with realistic mathematics education”. IndoMS-JME, Vol. 5, No. 1, pp. 27-34, 2014.

[35] H. Büyükikiz Kütküt. "Examining the use of realistic mathematics education approach in secondary school mathematics lessons and its effect on student achievement" (Unpublished Master Thesis). Çukurova University, 2017.

[36] K. Karataş, N. C. Aksoy \& D. Çakmak "The Effect of Realistic Mathematics Education on the Success of 5th Grade Students in Decimal Notation" International Journal of Science and Education, Vol. 4, No. 2, pp. 111-126, 2021. i This article is derived from the master thesis titled “The Effect of Realistic Mathematics Education on Academic Success, Motivation and Retention of
5th Grade Students" made within the Social Sciences Institute of Afyon Kocatepe University. 